\title{
Effects of Solar Radiation on Collagen-Based Biomaterials
}

\author{
Alina Sionkowska, ${ }^{1}$ Marcin Wiśniewski, ${ }^{1}$ Joanna Skopińska, ${ }^{1}$ and Diego Mantovani ${ }^{2}$ \\ ${ }^{1}$ Faculty of Chemistry, Nicolaus Copernicus University, Gagarina 7, 87-100 Torun, Poland \\ ${ }^{2}$ Laboratory for Biomaterials and Bioengineering, Laval University and University Hospital Research Center, \\ Québec City, Canada G1K 7P4
}

Received 16 February 2006; Accepted 4 May 2006

\begin{abstract}
The effect of solar radiation on collagen and collagen/synthetic polymer blends in the form of thin films and solutions has been studied by UV-VIS and FTIR spectroscopies. Films and solutions of collagen blended with poly(vinyl alcohol) (PVA) and poly(vinyl pyrrolidone) (PVP) were irradiated by solar light. It was found that UV-VIS spectra, which characterize collagen, collagen/PVA, and collagen/PVP blended films, were significantly altered by solar radiation. FTIR spectra of collagen, collagen/PVA, and collagen/PVP films showed that after solar irradiation, the positions of Amide A bands were shifted to lower wavenumbers. There was not any significant alteration in the position of Amide I and Amide II bands of collagen and its blends after solar radiation. The effect of solar UV radiation in comparison with artificial UV radiation has been discussed.
\end{abstract}

Copyright (c) 2006 Alina Sionkowska et al. This is an open access article distributed under the Creative Commons Attribution License, which permits unrestricted use, distribution, and reproduction in any medium, provided the original work is properly cited.

\section{INTRODUCTION}

Sunlight is a key environmental factor in almost all ecosystems, and the many ecological effects of visible and infrared wavelengths have been well established. In living organisms sunlight has a profound effect on premature skin aging and skin cancer [1-3].

Naturally occurring polymers absorb solar radiation and undergo photolytic, photo-oxidative, and thermal-oxidative reactions that result in the degradation of the material $[4,5]$. The degradation suffered by biopolymeric materials can lead to loss of mechanical properties which limit their performance. In sunlight mainly the ultraviolet radiation determines the useful lifetime of many materials. Any increase in the UV content in terrestrial solar radiation due to a partial depletion of the stratospheric ozone layer is therefore expected to have an impact on biopolymers. Moreover, for biopolymers the humidity and air temperature during exposure have a large influence on photodegradation. For synthetic polymers it was found that the samples kept at the lower temperatures deteriorated much more slowly than those at ambient temperature although both were exposed to the same dose of solar radiation [5].

Collagen is the main protein of connective tissue and the main component of skin [6-8]. It is widely used as a biomaterial, which is often exposed to solar radiation. The interaction of solar radiation with collagen in vitro has been studied previously [9]. The solar radiation altered the properties of the collagen films and caused changes in the conformation of the collagen molecule but did not lead to the cleavage of the chain. Artificial UV irradiation can induce crosslinks into collagen fibrils. However, this is complicated by peptide bond scission events that may also occur through free radical mechanisms [10-20].

In this paper the results obtained for collagen-based materials after solar radiation at Plataforma Solar de Almería in Spain are presented.

\section{EXPERIMENTAL DETAILS}

Collagen was obtained in our laboratory from tail tendons of young albinos' rats. We used the same method of extraction as previously employed [16, 17]. After washing in distilled water these tendons were dissolved in $0.4 \mathrm{M}$ acetic acid. Collagen films were obtained by casting the solution onto a glass plate or $\mathrm{CaF}_{2}$ spectrophotometric windows. After solvent evaporation, samples were dried under air at room temperature.

PVA and PVP were purchased from Sigma as a powder. The powder was dissolved in $0.4 \mathrm{M}$ acetic acid. Collagen/PVA and collagen/PVP blends were prepared by mixing of appropriate volumes of collagen and PVA or PVP in acetic acid such that solutions were produced containing collagenpolymer blends with a final weight ratio $1: 1$. Films were obtained by casting the solution onto glass plates or $\mathrm{CaF}_{2}$ 
TABLE 1: Doses of solar radiation during the specimens exposition.

\begin{tabular}{ccccc}
\hline Day & Hours & $\begin{array}{c}\text { Global radiation } \\
\left(\mathrm{x} 10^{6} \mathrm{~J} / \mathrm{m}^{2}\right)\end{array}$ & $\begin{array}{c}\mathrm{UV}(\mathrm{A}+\mathrm{B}) \\
\left(\mathrm{x} 10^{4} \mathrm{~J} / \mathrm{m}^{2}\right)\end{array}$ & $\begin{array}{c}\text { Time of } \\
\text { irradiation (days) }\end{array}$ \\
\hline 03.06 .2003 & - & 0 & 0 & 0 \\
04.06 .2003 & $8.50-12.50$ & 3.3 & 1.8 & - \\
04.06 .2003 & $13.30-15.30$ & 5.9 & 3.5 & - \\
05.06 .2003 & $9.00-12.00$ & 11.8 & 6.0 & 2 \\
05.06 .2003 & $12.40-15.40$ & 21.6 & 12.2 & - \\
06.06 .2003 & $9.20-12.40$ & 29.8 & 16.0 & - \\
06.06 .2003 & $13.17-15.30$ & 37.5 & 21.1 & 4 \\
09.06 .2003 & $9.05-12.10$ & 44.5 & 24.1 & 4 \\
09.06 .2003 & $12.42-15.30$ & 54.4 & 30.8 & \\
\hline
\end{tabular}

spectrophotometric windows. After solvent evaporation, the samples were dried in air at room temperature. The samples in the form of thin films of pure collagen, collagen/PVA, and collagen/PVP blends were irradiated under air, at a temperature range of $29-42^{\circ} \mathrm{C}$, by solar radiation at the Plataforma Solar de Almería, Spain, during 6 days in June 2003. The Plataforma Solar de Almería (PSA) is the largest center for research, development, and testing of concentrating solar technologies in Europe. The intensity of solar radiation including UV-A and UV-B during the exposure was constantly measured and the values of the dose are listed in Table 1. The intensity of the incident light was measured using a global UV radiometer (KIPP \& ZONEN, model CUV3), mounted on the platform tilted at $37^{\circ}$ (same angle as the CPC reactor), which provides data in terms of incident $\mathrm{W}_{\mathrm{UV}} \mathrm{m}^{-2}$.

The UV-VIS absorption spectra of the collagen specimens, before and after solar irradiation, were recorded with a Shimadzu spectrophotometer (Model UV-1601PC). Data collection and plotting were accomplished by the UVPC program and computer data station supplied by the manufacturer.

IR spectra were obtained using a spectrophotometer (Mattson Genesis II (USA)). Spectra were recorded by absorption mode at $4 \mathrm{~cm}^{-1}$ intervals and 16-times scanning. The functional groups in collagen and chitosan and their corresponding chemical characteristics can be observed from FTIR spectra in the wavelength range of $4000-600 \mathrm{~cm}^{-1}$.

\section{RESULTS AND DISCUSSION}

The absorption spectra of collagen films reveal absorption in the $250-280 \mathrm{~nm}$ region. The UV-VIS spectra that characterize the collagen films were significantly altered after global solar irradiation (Figure 1); irradiation of the collagen films by solar radiation leads to a minor increase in overall absorption, most notably between 240 and $300 \mathrm{~nm}$. This may be due to the changing optical properties of the collagen films. We know that artificial UV irradiation causes changes in the conformation of the collagen molecule (i.e., helix-coil

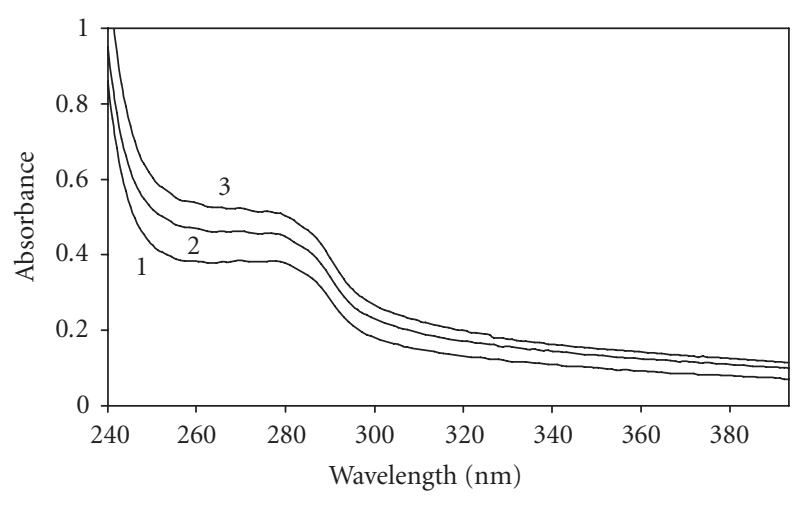

FIGURE 1: UV-VIS spectra of collagen before (curve 1) and after 2 days (curve 2) and 5 days (curve 3 ) of solar irradiation (key to time and dose of solar radiation in Table 1).

transition). The increased presence of a coil structure and the progressive loss of the helical character of collagen bring about an overall increase in the scattering level of the sample [15-17]. We can hypothesize that solar radiation containing UV-A and UV-B (see Table 1) also cause changes in conformation of the collagen molecule. After irradiation, the peak at $275 \mathrm{~nm}$ is less well pronounced, becoming more shoulderlike with increasing irradiation time. Solar radiation altered also the optical properties of collagen/PVA and collagen/PVP films. The changes of absorbance at $275 \mathrm{~nm}$ with dose of solar irradiation for collagen and its blends with other polymers are presented in Figure 2 (doses are listed in Table 1). The values of absorbance at $275 \mathrm{~nm}$ have been chosen for comparison of alterations by solar irradiation of collagen and its blends with other polymers. The absorption spectra of synthetic polymers usually do not show clear, characteristic peaks in the UV-VIS region.

For collagen/PVP blends (ratio $1: 1$ ), there is only a smaller difference between absorption/scattering after irradiation than in pure collagen. For the blends of collagen/PVA the alterations in UV-VIS spectra are bigger than that of pure 


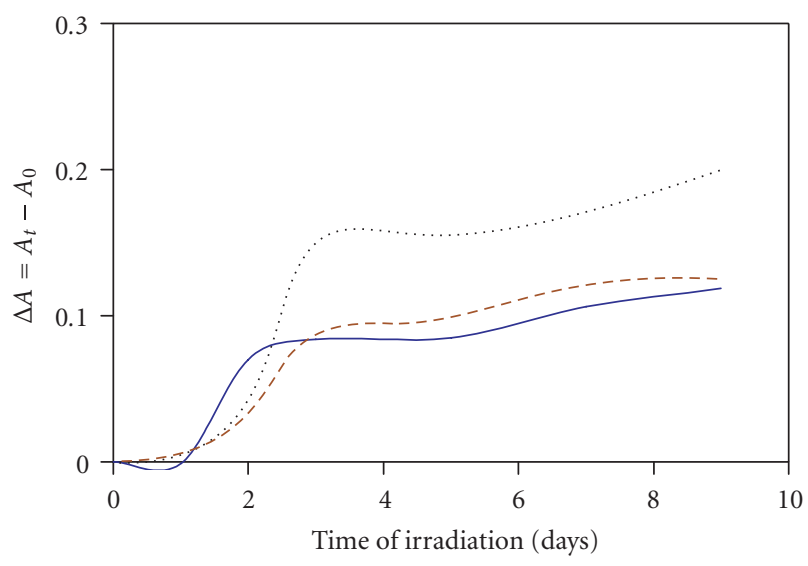

FIgure 2: The changes of absorbance at $275 \mathrm{~nm}$ during solar irradiation of collagen (solid curve), collagen/PVA (dashed curve), and collagen/PVP films (dotted curve), key to time and dose of solar radiation in Table 1.

TABLE 2: The position of Amide bands in FTIR spectra of collagen and collagen-based biomaterials after solar radiation (key to time and dose of solar radiation in Table 1).

\begin{tabular}{|c|c|c|c|c|c|c|}
\hline \multirow{2}{*}{ Sample } & \multicolumn{5}{|c|}{ Characterisctic bands $\left(\mathrm{cm}^{-1}\right)$} & \multirow{2}{*}{ Time of irradiation (days) } \\
\hline & Amide A & Amide B & $=\mathrm{CH}_{2}$ & Amide I & Amide II & \\
\hline \multirow{4}{*}{ Collagen } & 3315 & 3079 & 2936 & 1638 & 1547 & 1 \\
\hline & 3311 & 3071 & 2935 & 1634 & 1546 & 2 \\
\hline & 3309 & 3078 & 2940 & 1635 & 1547 & 3 \\
\hline & 3301 & 3064 & 2950 & 1634 & 1547 & 4 \\
\hline \multirow{4}{*}{$\begin{array}{c}\text { Collagen/PVP } \\
\text { blend }\end{array}$} & 3329 & 3087 & 2935 & 1644 & 1550 & 1 \\
\hline & 3322 & 3088 & 2953 & 1644 & 1550 & 2 \\
\hline & 3323 & 3086 & 2953 & 1645 & 1551 & 3 \\
\hline & 3321 & 3091 & 2955 & 1641 & 1549 & 4 \\
\hline \multirow{4}{*}{$\begin{array}{c}\text { Collagen/PVA } \\
\text { blend }\end{array}$} & 3316 & 3079 & 2937 & 1642 & 1548 & 1 \\
\hline & 3321 & 3067 & 2937 & 1642 & 1550 & 2 \\
\hline & 3318 & 3080 & 2938 & 1648 & 1549 & 3 \\
\hline & 3310 & 3088 & 2928 & 1641 & 1548 & 4 \\
\hline
\end{tabular}

collagen. This phenomenon is connected with miscibility of the components of the blend. Collagen and PVP are miscible [21], so the blend is homogenous. However, collagen/PVA are immiscible, so the film obtained from the blend is not completely transparent [22]. In artificial conditions during irradiation with UV light emitting $254 \mathrm{~nm}$ usually the blends were less photochemically stable than pure collagen [23]. However, artificial UV light was very energetic and its energy was sufficient to break chemical bonds. It has been found before that the presence of synthetic polymer in collagen material alters both the photochemical stability of collagen and the processes which lead to the increase of absorption, that is, photodegradation (with scission of bonds in the main chains) or phototransformation (with changes in the conformation of collagen molecules) [24].
The FTIR spectra of collagen are shown in Figure 3. Infrared spectra of proteins and synthetic polypeptides indicate a number of bands attributed to peptide bonds. They may be useful for further characterization of the bound water molecules and hydrogen bonds in collagen. Their positions are sensitive to changes in the conformation of the molecules [24]. The Amide A band of collagen (associated with the NHstretching frequency) is usually found at $3315-3330 \mathrm{~cm}^{-1}$; the Amide B band at $3080 \mathrm{~cm}^{-1}$; the Amide I band at 1630 $1650 \mathrm{~cm}^{-1}$; and the Amide II band is centered in the range of $1530-1555 \mathrm{~cm}^{-1}$. The Amide II band has a complex nature with its vibrational source in both the NH deformation and $\mathrm{CN}$ stretching modes. In our sample the Amide A band is shifted after solar irradiation to lower wavenumbers, but Amide I and II are not altered (Table 2). These shifts 


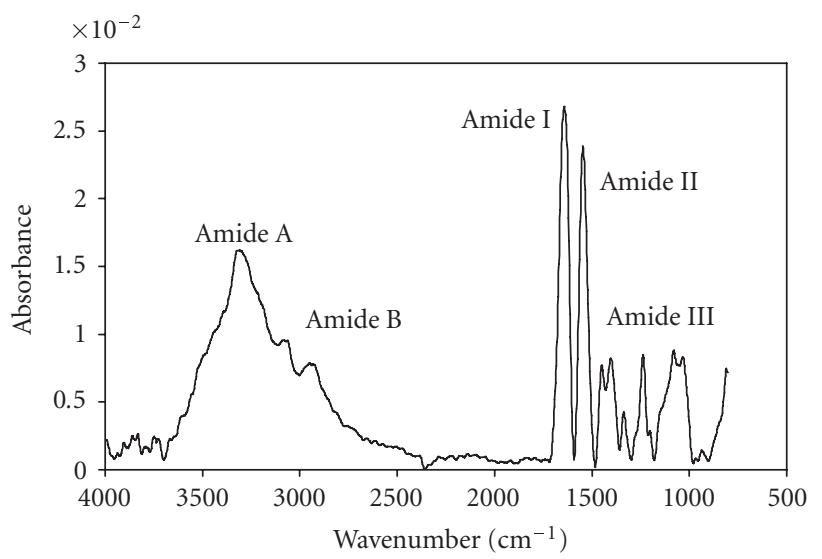

Figure 3: FTIR spectra of a collagen film. The Amide A, B, I, and II bands appear shifted to lower wavenumbers after solar irradiation.

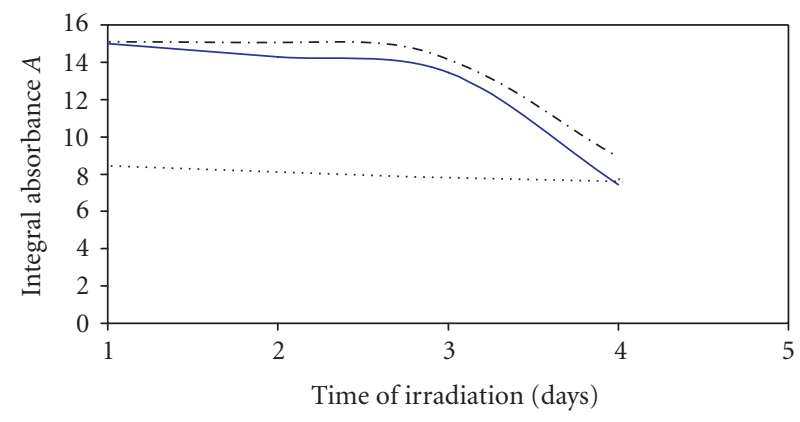

Figure 4: The changes of integral absorbance of Amide A band in FTIR spectra during solar irradiation of collagen (solid curve), collagen/PVA (dotted curve), and collagen/PVP films (dashed-dotted curve), key to time and dose of solar radiation in Table 1.

are possibly due to the scission of hydrogen bonds on exposure to UV irradiation from the sun: hydrogen bonds are necessary to maintain the helical structure of collagen. Similar shifts were observed for collagen/PVP and collagen/PVA blend (Table 2).

Using the FTIR method the changes in integral absorbance of the Amide bands after an extended period of solar irradiation were observed. Integral absorbance of Amide bands A, I, and II in collagen decrease after UV irradiation (Figures 4, 5, and 6). Integral absorbance for Amide A band collagen/PVA is nearly unchanged after UV irradiation (Figure 4). For collagen/PVP blends the changes of integral absorbance of Amide bands (A and II) are similar to those for pure collagen (Figures 4 and 6). The integral absorbance of the Amide A band at $3315-3330 \mathrm{~cm}^{-1}$ is much smaller after solar irradiation than for nonirradiated specimens. This fact points out that water is loosely bound to the collagen films (Figure 4).

Structural changes on the surface of collagen films were induced by solar irradiation. These have been observed using the microscope. The microphotographs of nonirradiated and

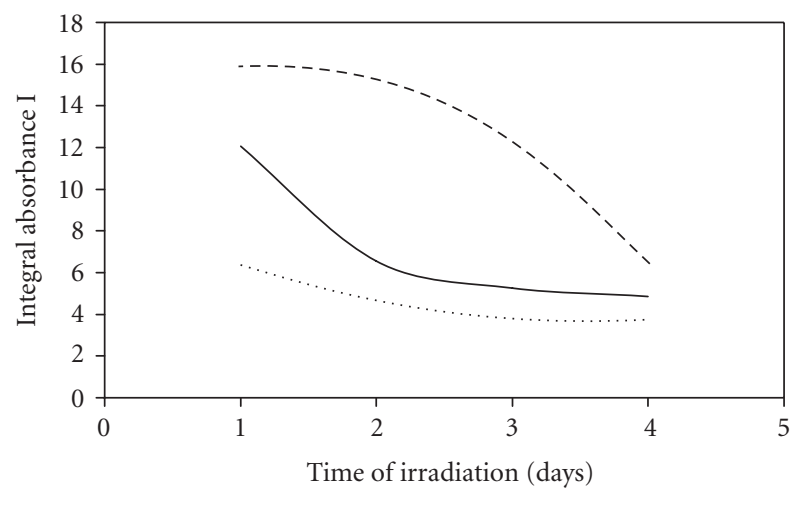

FIGURE 5: The changes of integral absorbance of Amide I band in FTIR spectra during solar irradiation of collagen (solid curve), collagen/PVA (dotted curve), and collagen/PVP films (dashed curve), key to time and dose of solar radiation in Table 1.

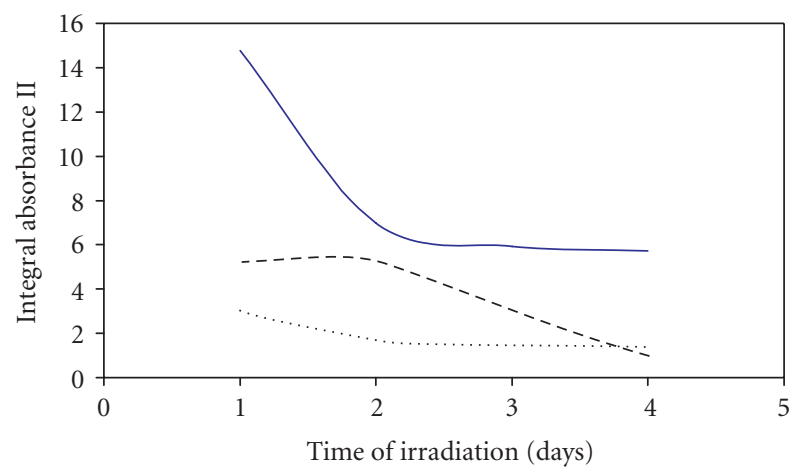

FIGURE 6: The changes of integral absorbance of Amide II band in FTIR spectra during solar irradiation of collagen (solid curve), collagen/PVA (dotted curve), and collagen/PVP films (dashed curve), key to time and dose of solar radiation in Table 1.

irradiated collagen-based films are shown in Figure 7. Due to the irradiation by solar light being carried out in open air, the specimens were usually covered by dust and other small particles supplied by the wind. We could observe the effects of these impurities on the surface of almost all specimens. This fact disrupts our ability to discuss the effect of solar UV light directly on the surface of the specimens. However, for all the films, we observed wrinkles and microcracks after solar irradiation which was the effect of loss of water bound to collagen.

\section{CONCLUSIONS}

The solar radiation alters the properties of collagen, collagen/PVA, and collagen/PVP films. Collagen/PVA films in the conditions of the experiment were more resistant to the action of solar radiation than collagen films. UV-VIS and FTIR spectroscopies have shown that solar irradiation causes the changes in conformation of the collagen molecule. The surface properties of thin films were altered by solar radiation. Microscopic photographs have shown that irradiated 


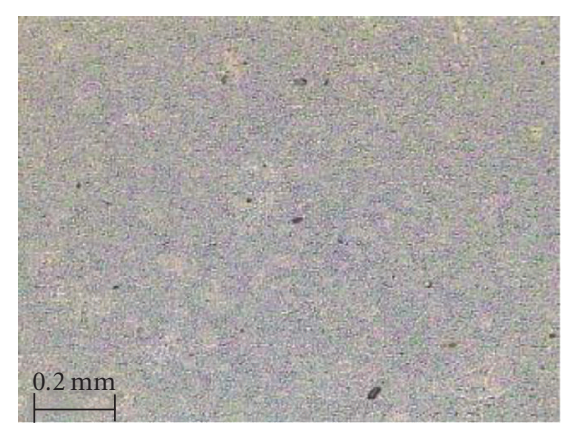

(a) 1 day

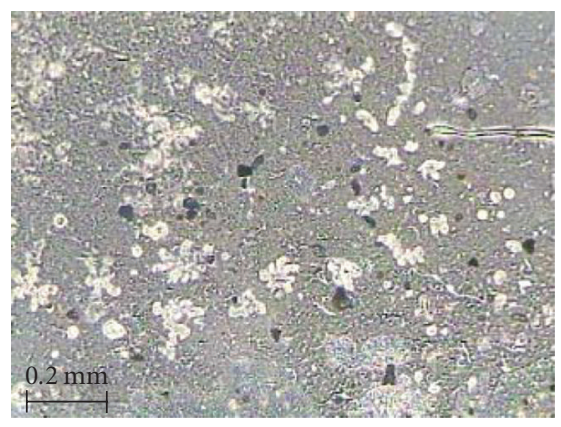

(c) 3 days

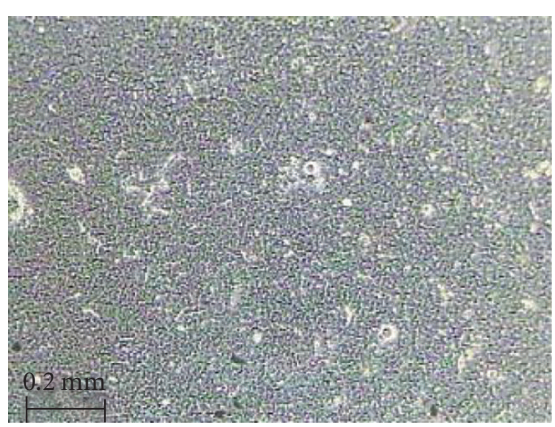

(b) 2 days

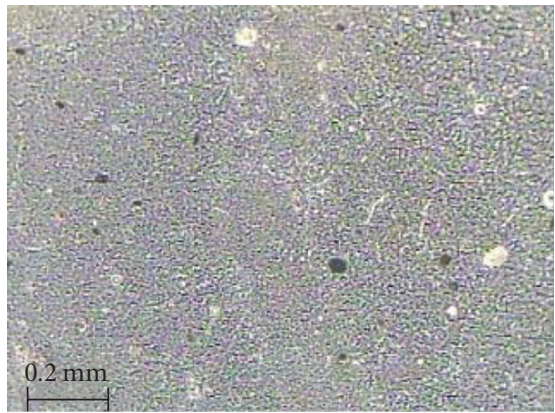

(d) 4 days

FIGURE 7: Microphotograph of collagen films before and after different doses (Table 1) of solar irradiation.

collagen films have evident surface changes. In the experiment the specimens were exposed to all wavelengths of sun light, so the effects of other components of sun light than UVB and UVA may give different effects than the artificial source of UV.

\section{ACKNOWLEDGMENTS}

Financial support from NATO (Grant no. CBP.EAP.CLG 982215), European Commission by the "Improving Human Potential" Programme HPRI-CT-2001-00160, and from the Ministry of Science and Information Society Technologies (MNII, Poland) Grant no. 3T08E 3829 is gratefully acknowledged.

\section{REFERENCES}

[1] F. R. de Gruijl, "Skin cancer and solar UV radiation," European Journal of Cancer, vol. 35, no. 14, pp. 2003-2009, 1999.

[2] L. Rittié and G. J. Fisher, "UV-light-induced signal cascades and skin aging," Ageing Research Reviews, vol. 1, no. 4, pp. 705$720,2002$.

[3] D. E. Heck, D. R. Gerecke, A. M. Vetrano, and J. D. Laskin, "Solar ultraviolet radiation as a trigger of cell signal transduction," Toxicology and Applied Pharmacology, vol. 195, no. 3, pp. 288-297, 2004.

[4] J. F. Rabek, Polymer Degradation, Chapman and Hall, London, UK, 1995.
[5] A. L. Andrady, S. H. Hamid, X. Hu, and A. Torikai, "Effects of increased solar ultraviolet radiation on materials," Journal of Photochemistry and Photobiology B: Biology, vol. 46, no. 1-3, pp. 96-103, 1998.

[6] A. Rich and F. H. C. Crick, "The molecular structure of collagen,” Journal of Molecular Biology, vol. 3, pp. 483-506, 1961.

[7] R. D. B. Fraser, T. P. MacRae, and E. Suzuki, "Chain conformation in the collagen molecule," Journal of Molecular Biology, vol. 129 , no. 3, pp. 463-481, 1979.

[8] A. J. Bailey and R. G. Paul, "Collagen: A not so simple protein," Journal of the Society of Leather Technologies and Chemists, vol. 82, no. 3, pp. 104-110, 1998.

[9] A. Sionkowska, "Effects of solar radiation on collagen and chitosan films," Journal of Photochemistry and Photobiology B: Biology, vol. 82, no. 1, pp. 9-15, 2006.

[10] T. Miyata, T. Sode, A. L. Rubin, and K. H. Stenzel, "Effects of ultraviolet irradiation on native and telopeptide-poor collagen," Biochimica et Biophysica Acta, vol. 229, no. 3, pp. 672680, 1971.

[11] Y. Kato, S. Uchida, and S. Kawakishi, "Oxidative degradation of collagen and its model peptide by ultraviolet irradiation," Journal of Agricultural and Food Chemistry, vol. 40, no. 3, pp. 373-379, 1992.

[12] A. Sionkowska and A. Kamińska, "Thermal helix-coil transition in UV irradiated collagen from rat tail tendon," International Journal of Biological Macromolecules, vol. 24, no. 4, pp. 337-340, 1999.

[13] K. S. Weadock, E. J. Miller, E. L. Keuffel, and M. G. Dunn, "Effect of physical crosslinking methods on collagen-fiber durability in proteolytic solutions," Journal of Biomedical Materials Research, vol. 32, no. 2, pp. 221-226, 1996. 
[14] A. Torikai and H. Shibata, "Effect of ultraviolet radiation on photodegradation of collagen," Journal of Applied Polymer Science, vol. 73, no. 7, pp. 1259-1265, 1999.

[15] A. Sionkowska, A. Kamińska, C. A. Miles, and A. J. Bailey, "The effect of UV radiation on the structure and properties of collagen," Polimery/Polymers, vol. 46, no. 6, pp. 379-389, 2001.

[16] A. Kamińska and A. Sionkowska, "Photochemical transformations in collagen in the presence of $\beta$-carotene," Journal of Photochemistry and Photobiology A: Chemistry, vol. 96, no. 1-3, pp. 123-127, 1996.

[17] A. Sionkowska and A. Kamińska, "Changes induced by ultraviolet light in fluorescence of collagen in the presence of $\beta$-carotene," Journal of Photochemistry and Photobiology A: Chemistry, vol. 120, no. 3, pp. 207-210, 1999.

[18] Y. Kato, K. Uchida, and S. Kawakishi, "Aggregation of collagen exposed to UVA in the presence of riboflavin: a plausible role of tyrosine modification," Photochemistry and Photobiology, vol. 59, no. 3, pp. 343-349, 1994.

[19] A. Sionkowska, "Photochemical transformations in collagen in the presence of melanin," Journal of Photochemistry and Photobiology A: Chemistry, vol. 124, no. 1-2, pp. 91-94, 1999.

[20] C. A. Miles, A. Sionkowska, S. L. Hulin, T. J. Sims, N. C. Avery, and A. J. Bailey, "Identification of an intermediate state in the helix-coil degradation of collagen by ultraviolet light," Journal of Biological Chemistry, vol. 275, no. 42, pp. 33014-33020, 2000.

[21] A. Sionkowska, "Interaction of collagen and poly(vinyl pyrrolidone) in blends," European Polymer Journal, vol. 39, pp. 2135-2140, 2003.

[22] A. Sionkowska, J. Skopińska, and M. Wiśniewski, "Photochemical stability of collagen/poly (vinyl alcohol) blends," Polymer Degradation and Stability, vol. 83, no. 1, pp. 117-125, 2004.

[23] A. Sionkowska, M. Wiśniewski, J. Skopińska, C. J. Kennedy, and T. J. Wess, "The photochemical stability of collagen - chitosan blends," Journal of Photochemistry and Photobiology A: Chemistry, vol. 162, no. 2-3, pp. 545-554, 2004.

[24] A. Sionkowska, "Modification of collagen films by ultraviolet irradiation," Polymer Degradation and Stability, vol. 68, no. 2, pp. 147-151, 2000. 


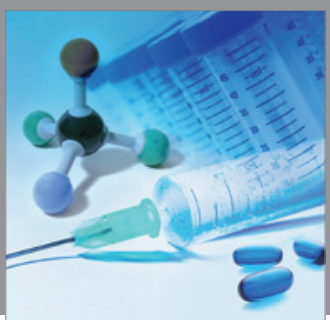

International Journal of

Medicinal Chemistry

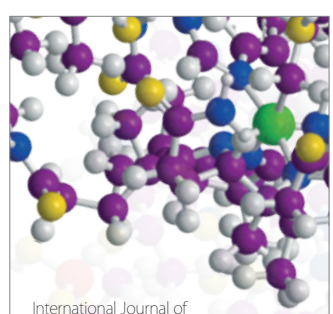

Carbohydrate Chemistry

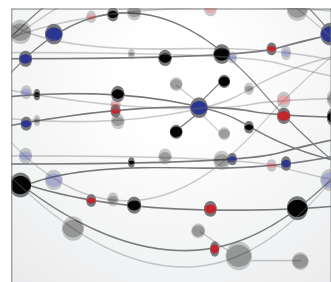

The Scientific World Journal
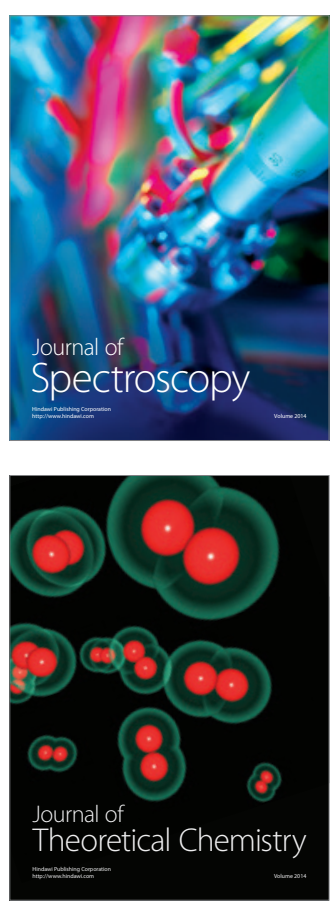
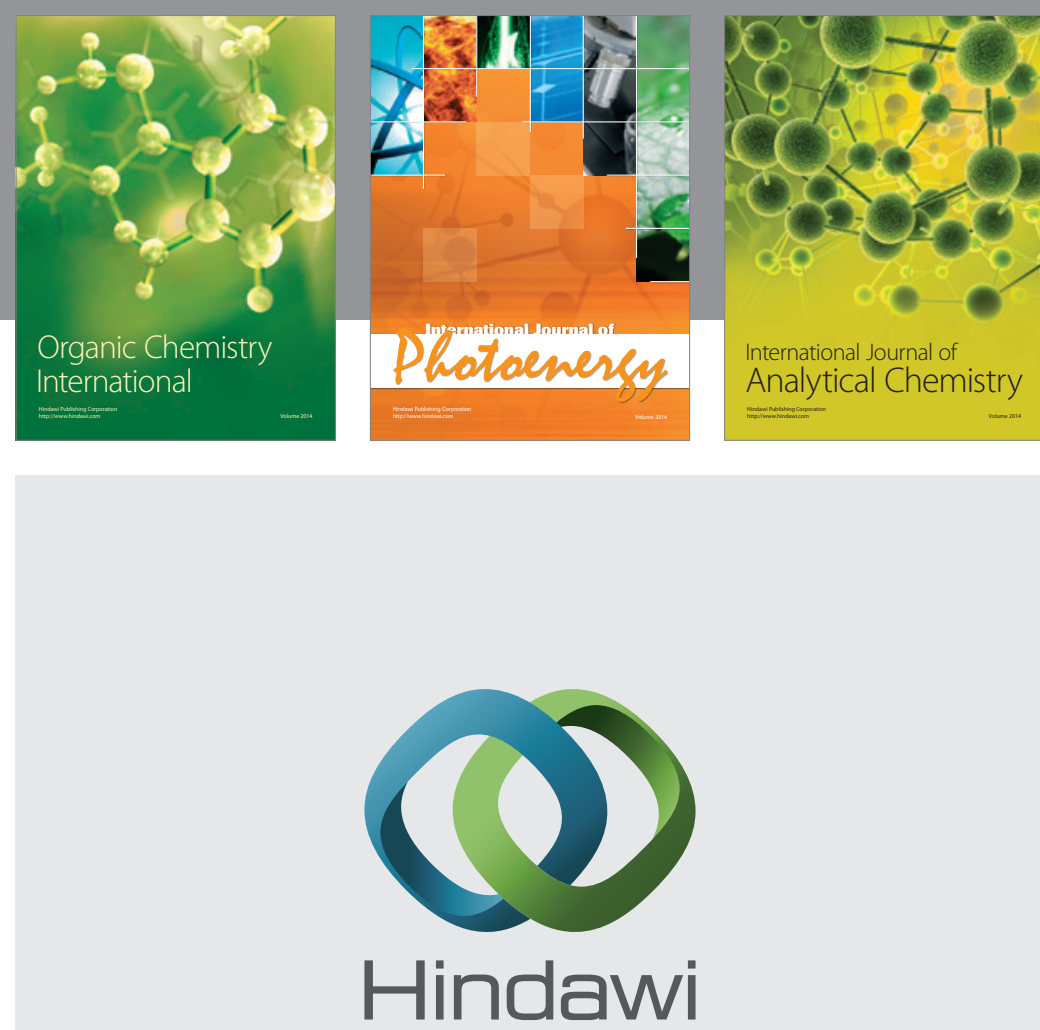

Submit your manuscripts at

http://www.hindawi.com
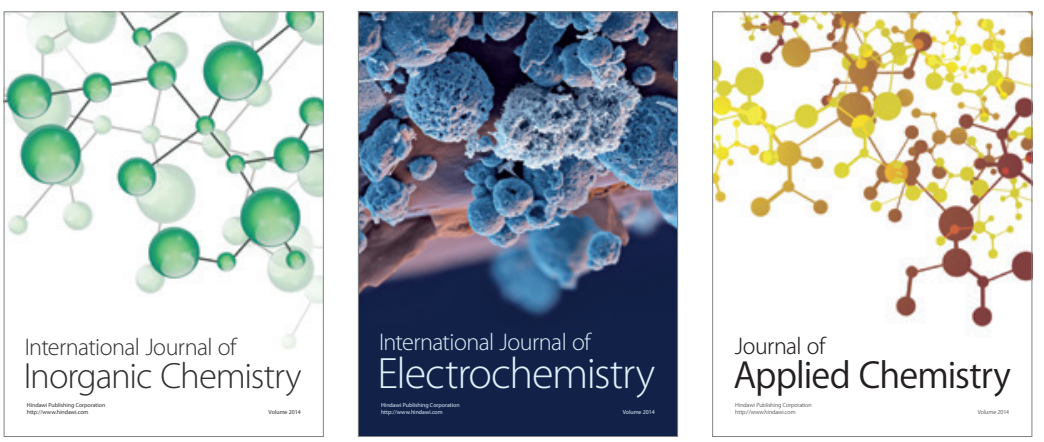

Journal of

Applied Chemistry
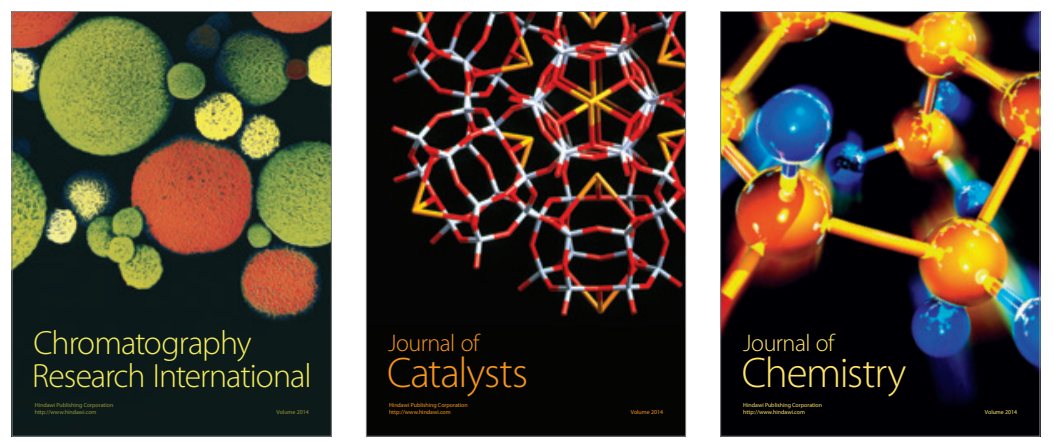
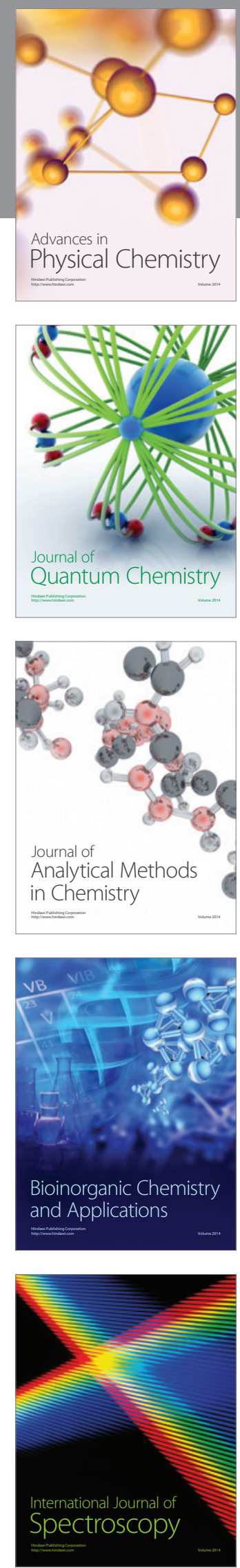